Artigos

Katia A. Agostinho '

\title{
O estágio na educação infantil no curso de peda- gogia: nova configuração, novos desafios e outros nem tão novos assim
}

A reflexão aqui proposta sobre o estágio curricular do curso de pedagogia na educação infantil abordará o seu caráter novidável para os estudantes do curso no tocante a aproximação intensa entre teoria e prática, ao estabelecimento da relação entre universidade e rede pública de educação infantil com o convívio nos contextos de pré-escolas e creches em que incide na formação inicial e continuada na docência, a relação sistemática com a professora orientadora do estágio como interlocutora privilegiada desse processo de formação e o exercício efetivo nos instrumentos da ação pedagógica: observação, registro, planejamento, documentação e avaliação. Em seu desenvolvimento será tratado da especificidade da área e consequentemente do estagiar nela para então, brevemente, apresentar alguns dos desafios e dilemas que temos enfrentado nesta tarefa de vivermos o estágio curricular na educação infantil no curso de pedagogia.

Palavras-chave: Pedagogia; Formação Docente; Estágio Curricular.

\section{The traineeship in early childhood education in the course of pedagogy: new configuration, new challenges and other not so new as well}

Abstract: The reflection proposed here about the traineeship course pedagogy in early childhood education discuss its new character for students of the course regarding the intense connection between theory and practice, the correlation between university and public schools for children's education and living in the contexts of pre-schools and kindergartens as it relates in initial and continuing training in teaching, systematic relationship with the guiding teacher internship as a privileged interlocutor of this training process and the effective exercise of pedagogical tools in action: observation, recording, planning, documentation and evaluation. In its development is handled in the area and consequently the specificity of her internship for then briefly present some of the challenges and dilemmas that we faced in this task we live stage curriculum in early childhood education in pedagogy courses.

Keywords: Pedagogy; Teacher Training, Curricular Training.

I Doutora em Estudos da Criança no Centro de Educação do Departamento de Metodologia de Ensino e do Programa de Pós-graduação em Educação da Universidade Federal de Santa Catarina. Pesquisadora do NUPEIN/UFSC. 
Os estágios já realizados, somados aos resultados de pesquisas sobre os profissionais de educação infantil, as crianças, a infância e a sua educação, impulsionam esta reflexão e aprofundamento. Como professora orientadora do estágio curricular na Educação Infantil no curso de Pedagogia de uma universidade federal, vivo processos de aprendizagens, questionamentos e inquietações diante das diferentes experiências que se efetivaram nessa trajetória.

Saliento a importante contribuição que os diferentes sujeitos partícipes nesses processos trazem: os estudantes que, com suas inquietações sobre o vivido no estágio curricular, tensionam muitos dos encaminhamentos do mesmo, os profissionais dos diferentes campos de estágio com os quais convivemos, e nossos pares, instigando-me a esta tentativa de reflexão e aprofundamento.

Enfatizo aqui sobre o lugar da experiência que nos remete a possibilidade de tal gesto implicar numa

espécie de encarnação do ocorrido, naquele que narra, para proporcionar aos que escutam algo que é, justamente, da ordem da experiência. Ou seja, dá-se a experiência no ato mesmo do encontro entre o que narra e aquele que acolhe a narração. Em outras palavras, para além de uma "vivência" que é contada ao outro, trata-se aqui de um acontecido que transformou o sujeito-narrador, de tal forma que, ao assumir a tarefa criativa de transmissão, nesse gesto mostra-se um "algo a mais" do acontecido, situação que produz no ouvinte também uma nova experiência, passível de ser narrada para si mesmo e para um novo outro. (FISCHER, 2012, p. 1039).

O curso de pedagogia da UFSC, atualmente, realiza na sétima fase a experiência de estágio curricular em Educação Infantil. Com as novas Diretrizes Curriculares Nacionais para o Curso de Graduação em Pedagogia - Resolução n. 1, de 15/05/2006, do Conselho Nacional de Educação, preveem que todos os estudantes devem cursar as disciplinas específicas da Educação Infantil, incluindo o Estágio.

O Projeto Pedagógico do curso prevê que o estágio curricular obrigatório na Educação Infantil (Educação e Infância VII - estágio supervisionado em Educação Infantil) vise,

a atuação na docência em creches e pré-escolas da rede pública municipal baseada na definição de plano de ação pedagógica e análise de contextos educativos. É constituído por momentos de observação, registro e documentação de contextos de atuação, processos considerados fundamentais à elaboração de planos de ação que tenham como foco as relações educativas com as crianças de zero a seis anos. Os projetos de estágios/planos de ação são elaborados de forma partilhada com as instituições campo de estágio, mantendo-se dessa forma uma relação articulada entre universidade e rede pública. Os estágios são finalizados mediante a entrega do documento final - relatório crítico das intervenções realizadas. A avaliação do processo é feita conjuntamente com as instituições que participaram dos estágios, em seminário de socialização de experiência, evento realizado semestralmente na universidade. $O$ estágio é previsto para ocorrer na $7^{\text {a }}$ fase do curso, em concomitância com disciplinas que são suporte à elaboração do projeto de estágio e à ação docente neste nível de ensino. A carga horária é de 12 créditos (216 
horas), distribuídas em atividades nos locais de estágio e atividades de orientação com os professores responsáveis. (2008, p. 38).

Essa configuração, que ainda podemos considerar recente, nos convoca a refletir, pensar e ensaiar algumas análises possíveis para esse momento embrionário em que as primeiras experiências dessa roupagem de estágio se concretizam, considerando que até a escrita deste artigo temos apenas cinco semestres concluídos da referida disciplina, tal como se apresenta no novo currículo do curso iniciado no primeiro semestre de 2009.

\section{Estágio curricular - uma disciplina de novo tipo}

Tenho chamado o estágio curricular de uma disciplina de novo tipo, para atentarmos às suas especificidades. O estágio compreende o espaço-tempo curricular que permite o exercício de ampliação do olhar dirigido às crianças e à prática pedagógica, por meio da imersão no cotidiano educativo em creches e pré-escolas públicas, no encontro com o coletivo de sujeitos que dele participam: crianças, profissionais, familiares e comunidade. Nesse encontro, aprofunda a compreensão dos contextos educacionais, prevendo diferentes níveis de observação, análise e proposições, cultivando e qualificando a interlocução com os envolvidos direta e cotidianamente com a educação das crianças pequenas, ensaiando alternativas de atuação, potencializando o diálogo teoria-prática, como um ato/exercício que se inscreve pela não dicotomização.

Ao viver o estágio curricular os estudantes entram em um novo tipo de disciplina que exige o exercício de articulação entre teoria e prática intenso e sistemático. No exercitar-se na ação enquanto estagiárias(os), providas(os) do referencial teórico que receberam até esse momento no curso, realizam o exercício praxiológico, no sentido do que fazer, nos contextos educativos. Apresentando-se a necessidade do exercício de estudiosas(os) críticas(os) reflexivas(os) em que rememoram, revisitam o processo de formação anterior realizado no curso até o momento, e para além dele, para atuarem nos campos de estágio, assim como no exercício de sua profissão futura, ou mesmo presente, considerando-se aqueles estudantes que já atuam na profissão.

Localizam-se aí, nesse espaço-tempo de formação, na disciplina estágio curricular, que chamo de novo tipo, dificuldades e dilemas que se apresentam em realizar as conexões necessárias entre essas duas categorias. A Educação é uma área de ação-intervenção direta. É no estágio que 
os estudantes defrontam-se pela primeira vez com a necessidade de tradução das teorias estudadas ao longo do curso ao exercitarem-se em ensaios na prática pedagógica, num esforço de articulação entre teoria e prática, sem com isso negar as suas especificidades, considerando que a realidade educacional é sempre mais rica e complexa que as teorias que temos acerca dela.

A tarefa descrita acima, elemento constituidor do estágio curricular, é complexa e exige dedicarmos atenção sobre os elementos que constituem a complexidade anunciada. Além de ser novidável na vida dos estudantes, o exercício de conexão das teorias com a prática, enfrenta ainda o peso da tradição da dicotomização histórica do binômio teoria $\mathrm{X}$ prática. O pensamento dicotômico característico da modernidade, campo profícuo onde se alastraram e solidificaram os jargões de que "a teoria está longe da prática", "isso é só na teoria a prática é bem outra", "novos modismos" etc está longe de se localizar apenas no passado. Convivemos com o desafio de enfrentá-lo cotidianamente.

Os dualismos instaurados por um pensamento dicotômico moderno é problemático para a educação, particularmente pelo exercício contínuo que exige conexão/articulação entre teoria e prática, agora - enquanto estagiárias e para sempre - enquanto professoras.

O projecto da modernidade é fértil em dicotomias, o que em última instância se deve atribuir ao modelo de racionalidade cartesiana que lhe subjaz [...] esta característica do projeto da modernidade coexiste com uma outra, a ausência ou extrema deficiência de mediações entre as dicotomias. (SANTOS, 1990, p. 13-14).

Ao dar visibilidade às características do estágio curricular como disciplina que apresenta o exercício praxiológico por excelência, cruzado pelos desafios que as dicotomias da modernidade instauraram, incidindo ambos sobre teoria e prática, somam para a compreensão de sua complexidade. Nesse esforço temos de buscar pensamentos densos, ricos que sobrepostos, cruzados, interseccionados possam dialogar em linhas que se conectam e desconectam, aceitam as linhas de fuga e, nesse emaranhado, possam tecer com ousadia e compromisso as mediações que necessitamos realizar entre teoria e prática, para nos aproximar dos contextos educativos.

Ao tratar a temática das relações entre teoria e prática na formação de professores temos de evitar as retóricas vazias e adjetivações insuficientes para a compreensão dos problemas a enfrentar, que impedem a reflexão sobre sua complexidade ou sobre a diversidade de formas por meio das quais o problema tem sido abordado. $\mathrm{Na}$ defesa da "pluralidade de formas pelas quais um saber teórico- -proposicional (saber que) se relaciona com um saber operativo (saber fazer)" (CARVALHO, 
2011, p.308), para o enfrentamento de um problema amplo e complexo.

Precisamos de uma renovada atitude epistemológica, que faça aproximar teoria e prática, em um caminho de formação instigante, dinâmica, pulsante. Nela a documentação é nossa aliada fundamental, porque tensiona o aporte teórico diante das urgências que a prática o convoca, como exercício de reflexão, compreensão e ação. Caminho que, não é simples nem imediato, exige estudo, reflexão, trocas, compromisso, estrutura adequada para sua execução.

Os estudos de Bernarderte Gatti (2010) sobre currículos da pedagogia demonstram que a relação teoria-prática, proposta nos documentos legais e nas discussões da área, se mostra comprometida desde a base formativa. Observa nas ementas dos cursos

um evidente desequilíbrio na relação teoria-prática, em favor dos tratamentos mais teóricos, de fundamentos, política e contextualização e que a escola, como instituição social e de ensino, é elemento quase ausente nas ementas, o que leva a pensar numa formação de caráter mais abstrato e pouco integrado ao contexto concreto onde o profissionalprofessor vai atuar. (GATTI, 2010, p. 1372).

A autora constata que:

_ o currículo proposto pelos cursos de formação de professores tem uma característica fragmentária, apresentando um conjunto disciplinar bastante disperso;

_ a análise das ementas revelou que, mesmo entre as disciplinas de formação específica, predominam as abordagens de caráter mais descritivo e que se preocupam menos em relacionar adequadamente as teorias com as práticas. (GATTI, 2010, p.137I).

Na contraposição a fragmentação, na busca de uma prática mais orgânica e rica, aparece a importância de construir e instaurar o diálogo e trocas intensas entre os professores do curso, no sentido de construirmos e consolidarmos a indissociabilidade entre as disciplinas. Pensando e encaminhando práticas junto aos estudantes de aproximação as realidades educacionais durante toda a trajetória do curso nas diferentes disciplinas. Neste sentido ter em conta a importância de privilegiarmos os contextos educacionais públicos e suas diferenças sociais, culturais, geográficos etc. durante toda a trajetória do curso nas diferentes disciplinas.

No encaminhamento proposto acima quanto a relação que estabelecemos com a rede pública municipal de educação aparece outro elemento novidável na vida dos estudantes, em que saímos da universidade e vamos para os contextos educativos - creches e pré-escolas. Momento em que vamos habitar outra instituição e se colocam um conjunto de importantes elementos que temos de 
ter em conta.

$\mathrm{Na}$ relação com a rede o que temos chamado de partilha tem sido considerado um dos elementos constituídores do estágio, nela se efetiva nosso interesse de que o estágio incida sobre a riqueza do cruzamento de diferentes pontos de vista e tenha sua efetiva atuação-contribuição na formação continuada, momento de troca profícuo em aprendizagens para as estagiárias e todos os envolvidos, compreendendo ainda que possa advir dele contribuições para a área.

Esse saber e sensibilidade que marcam o nosso estágio vem de longa data, já indicado por Luciana Ostetto em 2000,

Um trabalho que, construído no encontro de estudantes-educadores no campus, com profissionais-educadores em campo, tem os olhos na realidade e vai nela penetrando através de um movimento de articulação de vozes, desejos e ações daqueles que estão em processo de formação inicial e daqueles que já estão atuando e que, no movimento, experimentam uma verdadeira formação em serviço (OSTETTO, 2000, p.20).

$\mathrm{Na}$ importante contribuição de Partilhando Olhares... em 2002, que reuniu Ana Beatriz Cerisara, Andréa Rivero, Alessandra Rotta Oliveira e Rosa Batista, esse grupo de professoras que debruçaram-se sobre a temática em diferentes experiências. As autoras também abordam acerca da relação que se estabelece entre a universidade e rede pública de educação:

estagiários e professores, estariam envolvidos no processo de observação, registro e reflexão acerca do cotidiano vivido pelas crianças pequenas no espaço da creche. Mais do que a atividade, teríamos a criança como foco... os professores das instituições estariam na posição de observadores e investigadores dos jeitos de ser criança neste espaço de educação e cuidado de meninos e meninas de 0 a 6 anos de idade. Os estagiários e professores, agindo como pesquisadores, partilhariam suas impressões sobre a realidade captada, descobrindo diferentes olhares sobre uma mesma situação, e talvez formulassem diferentes proposições para ampliar os repertórios culturais dos grupos infantis de forma individual e coletiva. Este processo envolve a construção de um espaço efetivo de compartilhamento de diferentes olhares e saberes sobre as crianças pequenas. (CERISARA et al, 2002, p.9).

Reiterado por Eloisa Rocha e Luciana Ostetto em 2008, quando as autoras afirmam que o estágio "só pode ser realizado quando a universidade e instituição estão de acordo e fazem um dialogo entre si.” (p.108). Indicando assim a necessidade do respeito mútuo onde,

as estagiárias, com observações, registros, analises e proposições põem em dialogo os fazeres na creche, muitas vezes apontando questões sobre o cotidiano da educação das crianças que são, também desafios para os próprios profissionais. Dessa forma, o estágio é um espaço aberto para o enfrentamento conjunto de tais questões, resultando aprendizagem para os profissionais da creche e para as estagiárias, profissionais em formação. (ROCHA e OSTETTO, 2008, p. 109-110). 
Assim,

Reafirma-se a importância do processo de valorização dos profissionais responsáveis pela organização e pela ação educativa, nas instituições de educação infantil com as quais dialogamos, implicando, necessariamente, no esforço de engajamento dos mesmos no processo de reflexão sobre sua própria prática e formação. (ROCHA e OSTETTO, 2008, p.|II).

Ainda sobre a importância do estágio com o encaminhamento do mesmo como espaço para a formação continuada dos professores em exercício, temos também o depoimento do "sujeito do lado de lá”, a coordenadora pedagógica de uma creche-campo de estágio:

Para nós, o estágio é considerado uma das três vias de formação em serviço. [...] A creche, ao participar desde a discussão do projeto de estágio, até a avaliação na sua conclusão, assume a sua responsabilidade, enquanto espaço de prática pedagógica e formação em serviço. Assim, quando aponta o que foi feito e dimensiona o que está por fazer, não apenas muda a sua prática como também contribui para a revisão e reformulação de alguns aspectos teóricos. [...] A partir desse encontro, vai-se construindo um fazer e um saber que não é apenas reprodução, mas ação, fruto de reflexão. (BROERING, 2008, p.l10).

Alonguei-me propositalmente na apresentação das diversas contribuições e, sujeitos que ocuparam diferentes posições, em tempos históricos variados em práticas de estágio, para adensar a defesa deste encaminhamento metodológico do estágio curricular na educação infantil e, contar com os mesmos para a compreensão e aprofundamento da temática. $\mathrm{Na}$ instauração dessas relações e práticas de partilha muitas questões tem-se colocado:

- como pensar e organizar a partilha coletivamente?

- o que os sujeitos do Outro lado pensam acerca dela?

- o interesse de participação do(a) professor(a) de fazer parte desse processo reflexivo-formativo proposto,

- o tempo e estrutura que as unidades campos de estágio tem para efetivá-la;

_ o cuidado de pensar a condução e os níveis os quais essa reflexão se efetivará, a linguagem e conteúdo utilizados, num plano ético de profundo compromisso com a educação da infância, demonstrando aqui a importância da atenção, cuidado e sutileza do papel do professor orientador que junto as(os) estagiarias(os) constrói o instrumento de conversa-reflexão1.

I O instrumento consta de sínteses dos registros das observações de campo, organizado pelos estudantes, sob a orientação da professora do estágio, são partilhadas com as professoras da turma e coordenação, num encontro em que ouvimos as apreciações das professoras e coordenadora do campo de estágio acerca dos conteúdos expressos e outros que porventura apareçam. Podemos ainda, apenas entregar o material construído quando não temos tempo para o encontro e realizamos conversas informais sobre o mesmo. 
A relação de estágio compreende todos os envolvidos no ato educativo. Ela é dialógica, polifônica, exigindo a presença, espaço, tempo para as singularidades de cada sujeito envolvido. Para que a mesma se estabeleça o respeito mútuo se faz indispensável e precisa ser cultivado, cuidado, mantido em atenção ao longo de todo processo.

Estudos em contextos de educação (CERISARA et al, 2002; ROCHA \& OSTETTO, 2008; KRAMER; NUNES \& CORSINO, 2011) têm anunciado o desafio de construir essa relação entre adultos que se ocupam de diferentes papéis no cotidiano educativo de modo respeitoso. O interesse é o de realizar uma relação que não incorra em práticas acusativas na apreciação das docências, mas também não se pretende que ela seja conivente com ou omissa a encaminhamentos que divirjam dos referenciais teóricos defendidos, desafiando-nos a construir um espaço-tempo de efetivo diálogo, ante as ideias e posturas dos professionais observados acerca da nossa opinião sobre a sua prática junto as crianças.

A relação que se estabelece não é direta e nem linear, não podemos ter a pretensão de enquanto instituição universitária oferecer respostas prontas e únicas às práticas pedagógicas. Compreendo que "toda interlocução, influência ou mudança [...] envolve mobilizações de várias ordens de conhecimento, condições políticas, estruturais e sociais, processos formativos, profissionais, etc." (ROCHA, 2012, p.3). Coloca-se a tarefa importante de instaurarmos um diálogo aberto, nem sempre consensual, mas com a potência de contribuir para avanços na prática pedagógica e na formação dos profissionais. Reconhecendo que,

os conhecimentos, as teorias, as concepções [...] circulam entre atores situados em diferentes setores, que rejeitam ou se apropriam deles a seu modo, devolvendo essas concepções modificadas ..., por meio de ações observadas, discursos colhidos e efeitos supostamente produzidos por sua atuação. (CAMPOS, 2009, p. 27I).

Por isso, é necessário traçar um itinerário que contrário a uma única interpretação válida, rechaça práticas esmagadoras legitimadas pelo discurso da ciência, da academia e permite a interpretação, partilha, negociação entre os sujeitos envolvidos de seus pontos de vista, de modo a funcionar na comunicação intersubjetiva com os sujeitos, numa relação em que se assume "uma comunicação não só no verbo, mas também no gesto e no signo, no movimento e no caminho, no silêncio e no sintoma, e dando espaço e direito a tais linguagens" (BECCHI, 1994, p.83), assumindo que o "olhar toca o outro", e, refletidamente, ter o cuidado de entender que "pousar o olhar sobre o outro não é um acontecimento anódino", é um "exercício de um poder", uma "experiência afetiva." (LE BRE- 
TON, 2009).

As observações e os registros das estagiárias e professoras são os deflagradores desse diálogo-aprofundamento-estudo-formação, instaurando assim reflexões, questionamentos que incidem sobre o cotidiano observado, fazendo um diálogo próximo com as teorias que nos inspiram da Pedagogia da Infância e outras, apostando num diálogo entre diferentes disciplinas que enriquecerá nossa capacidade de compreensão e análise.

Durante o estágio a observação, registro, planejamento, documentação e avaliação tomam preponderância e são vividas pelas estudantes com a presença e diálogo constante com a orientadora de estágio, que exerce o papel importante de interlocutora privilegiada acerca deste processo de aprendizagem, cabendo-lhe a tarefa de ao lê-los estabelecer as reflexões necessárias para seus aprofundamentos, orientando no sentido de vencermos práticas de observação e compreensão da realidade educativa de modo aligeirado, superficial, acusativo, apontando os encaminhamentos da área que sejam pertinentes para as diferentes abordagens que emergirem deste encontro. Aqui demarco outro caráter novidável do estágio curricular que é uma relação estreita, sistemática e contínua da professora orientadora de estágio com cada estudante.

Nas primeiras semanas das atividades efetivas no campo de estágio acontece um movimento intenso em torno das observações e registros, que indicam atenção ao importante papel que a orientação de estágio ocupa nas produções realizadas. Cabe à ela acompanhar próxima e sistematicamente os registros, estabelecendo um diálogo intenso e rico em reflexões e orientações dos aprofundamentos que se façam necessários, numa relação individualizada e coletiva, cuidadosa e próxima.

O ato de observar temporaliza-se em momentos diferenciados que o constituem em sua integralidade, os tenho nomeado como o tempo anterior, durante e depois.

No tempo anterior - o 'olho' que se prepara para observar se inspira em que fontes? Anteve pensando, refletindo, estudando, e se posiciona a partir:

- das Diretrizes Curriculares Nacionais para a Educação Infantil (Resolução CNE 5/2009);

- dos princípios do estágio;

- das concepção de criança e de sua educação.

No tempo durante - quando o 'olho' chega e encontra outros, um olho convite para o 
encontro, debruça-se sobre os universos infantis na tentativa de compreendê-los, busca os modos próprios de ser e estar criança no espaço educativo.

No tempo depois - o 'olho' que se retira, longe do pulsar do contexto observado, fica na companhia das notas de campo e memórias, aí intensifica o diálogo com as teorias para ensaiar tentativas de compreensões do observado.

O processo descrito das observações exige muito esforço para realizar o recorte, focar a observação no universo rico e plural do contexto educativo. Suportar o recorte é difícil, pois a tendência comum inicial é a de tentar observar tudo e todos. Vamos seguindo as pistas das recorrências de situações registradas, intensificando as descrições das mesmas na busca de superar o que parece óbvio, com atenção sistemática e riqueza de detalhes pormenorizados do observado. E quando chegamos às mesmas dialogamos com as teorias basilares da área para que possamos ampliar nossa capacidade de compreensão.

Após um conjunto de observações e registros nos arriscamos nos ensaios na docência compartilhada. Sendo importante frisar que nossas intervenções já acontecem desde o primeiro instante de relação: no olhar, no contato, na abertura às demandas das crianças, no envolvimento com a vida do grupo, do coletivo (importante frisar para não cair no esquecimento!). Penso que a marca, o traço desta intervenção se inscreve a partir dos princípios éticos, políticos e estéticos das Diretrizes Curriculares Nacionais para a Educação Infantil.

A ação pedagógica é um ato educacional que evidencia a sua intencionalidade. Nela o planejamento que defendemos se diferencia da ideia de programação, prescrição, já que a complexidade e riqueza da realidade exigem perturbar as ordenações, pensar e encaminhar novos trajetos e criações, obrigando a conexões que não são ingênuas, espontaneístas e nem uma mera arbitrariedade, fundam-se no conjunto de estudos que a área tem construído e seu diálogo próximo com outras diferentes, que neste exercício dialogam e informam-se, somados aos contributos das crianças que são captados nas observações e registros.

Importante questão se coloca - de onde nasce o planejamento com bases na Pedagogia da Infância, mais propriamente da Pedagogia da Educação Infantil?

_ a criança como ponto de partida, as crianças com que nos encontramos em nossas práticas pedagógicas, contextualizadas e cruzadas pelas diferentes categorias sociais que as atravessam: de 
classe, étnico-racial, de gênero, cultura, apresentadas a partir dos registros que temos das mesmas; _ os saberes da área, muitos deles já indicados nas DCNEI - brincadeira, interações e as linguagens, os Núcleos da Ação Pedagógica (ROCHA, 2010), mais os saberes sobre as crianças e as infâncias, advindo dos diálogos interdisciplinares, como as culturas infantis (corpo, afetos, humor, curiosidade, simultaneidade de ações etc);

_ do compromisso com o enriquecimento dos diferentes repertórios das crianças: culturais, artísticos, ambientais, científicos, tecnológicos;

_ tendo em conta as transições (creche _ pré-escola, pré-escola _ ensino fundamental).

Ao nos exercitarmos nos planejamentos e proposições de estágio partimos das observações realizadas acerca das crianças e das orientações da área, temos ainda de ter em conta e pensá-los no cruzamento da vida do grupo observado e do tempo de estágio que é um recorte. Coloca-se, assim, importantes tensionamentos que devem ser enfrentados com astúcia e sensibilidade.

Deve-se ainda ter em atenção a importância de compreensão de que no estágio aconteça um envolvimento direto, ativo nas relações ali estabelecidas, de higiene, alimentação, descanso, brincadeiras, interações, atividades, descobertas, curiosidades, conversas, explorações, diferentes linguagens e expressões experienciadas etc, fulcral para as estagiárias exercitarem-se nas ações que compõem a docência.

\section{Especificidade da área e do estágio nela}

Com a intenção de fornecer aos estudantes a compreensão da construção/consolidação da área, sua especificidade, as aulas iniciais dedicam-se a essa temática, assim como a própria feitura do plano de aula. Nele apresentamos os chamados 'mapas conceituais', que disponibilizam referências de estudos que tenham se dedicado à área e que contribuem para a formação do professor(a) de Educação Infantil. Compreendendo nossa incapacidade de tratar todas as referencias, assim como esgotar a mesma, mas esse roteiro nos serve como possibilidades de estudos para os estudantes durante sua trajetória profissional, como 'território de aprendizagens' que seguem no convívio - confronto com a realidade dos contextos educativos no exercício da profissão. Contribuindo, assim, na necessidade que a formação profissional tem de incluir "uma perspectiva crítico-reflexiva, que forneça aos professores os meios de um pensamento autônomo e que facilite as dinâmicas de autoformação 
participada”. (POPKEWITZ, 1997, p. 25 Apud Rocha \& Ostetto, 2008).

O estágio está conectado com os próprios desafios que a área vive na construção e consolidação de sua especificidade. A educação é um campo de disputas e, nela a educação infantil tem sua história. Nesse trajeto, com as contínuas transformações sociais, políticas, culturais e científicas que envolvem a infância, a criança e a sua educação em espaços formais e a própria formação de professores(as) no país, nos exige sempre novas conexões e desconexões, reencadeamentos perpétuos para o enfrentamento dos desafios que se colocam ao processo de formação que ocorre no Estágio na EI. Assim, mapear seus dilemas diante das tarefas que assume e revisitar contributos teóricos nessa temática coloca-se como tarefa importante na construção de um saber que assume sua historicidade, provisoriedade e incompletude.

A especificidade formativa da docência para EI, assume um caráter educativo próprio, ligados a dimensão educativa que integra o cuidado e a educação em compartilhamento com a família e o encontro com a infância.

Assumimos como foco do estágio as crianças, por reconhecermos a importância dessa tarefa pelo: i) - reconhecimento desse sujeito da educação invisibilizado no passado e largamente ainda no presente; ii) - aprendizagem, sensibilização, exercício de aproximação aos universos infantis por parte das estagiárias; iii) - contribuições possíveis que nessa aproximação-encontro, com os instrumentos de estágio para as práticas pedagógicas; ix) - contribuição no pacto ético que estabelecemos com o campo de estágio. Mas, este encaminhamento não ofusca que é a criança institucionalizada, que o foco da educação são as relações pedagógicas, travadas por adultos e crianças nos contextos educativos - creches e pré-escolas. Cuidamos assim a bipolarização e reconhecemos o silenciamento e invisibilização histórico das crianças nesse processo, na busca de modos mais compostos para a compreensão e aprofundamento dos processos educativos.

\section{Novo currículo, velhos dilemas?}

Com a implantação do novo currículo do curso de Pedagogia, em 2009, temos um conjunto de interrogações acerca dos caminhos eleitos ou circunstanciados. Sem a pretensão de aqui esgotá -los, apresentarei alguns deles como importantes para a condução da formação desejada.

Destaco primeiramente, pela contundência do desafio que se apresenta ao vivê-lo, a redução 
da carga horária do estágio: de 360 horas para 216 horas. A diminuição significativa do tempo incide sobre a profundidade com que se poderá abordar os conteúdos e processos previstos no estágio, já apontados na própria ementa da disciplina:

Diretrizes educativas e definições dos núcleos da ação pedagógica da atuação no estágio em Educação Infantil. Conhecimento dos campos de estágio e definição compartilhada dos projetos de estágio. Observação, registro, documentação e análise dos contextos e das relações educativas. Atuação docente. Socialização sistemática com os professores do campo de estágio. Elaboração do relatório de estágio: análise crítica das intervenções realizadas junto às unidades de Educação Infantil do sistema público de ensino.

A previsão, no Projeto Político Pedagógico do curso, de que o estágio ocorra em concomitância com disciplinas que darão suporte à elaboração do projeto de estágio e à ação docente, neste nível de ensino na mesma fase, não tem ocorrido, o que fragiliza a capacidade de adensarmos a sua feitura.

Ainda, o eixo que o transversaliza - Educação e Infância2 é um ganho substancial que precisa enfrentar a necessária tarefa de ser pensado em sua integralidade, afinar os conteúdos programáticos entre as disciplinas e que suas metodologias de encaminhamento estejam atentas à necessária estratégia de possibilitar contato das estudantes com as realidades educativas e exercitarem-se nos instrumentos da ação pedagógica.

E, finalmente, o compromisso assumido por nossa instituição, de universidade pública, com a construção e desenvolvimento de processos formativos voltados para o fortalecimento da escola pública, gratuita, de qualidade e com compromisso social, precisa ser mantido em atenção e firmeza no propósito estabelecido e aqui defendido, contemplando estratégias de estágio que possam incidir nas vertentes de formação inicial e continuada. Podendo contribuir neste quesito o encaminhamento e fortalecimento de estratégias que intensifiquem nossa capacidade de efetivarmos projetos que conjuguem ensino, pesquisa e extensão.

\section{Ainda, nestas margens que já me faltam...}

2 O curso tem a docência como princípio e, organiza-se para tal propósito formativo em torno de três eixos: educação e infância, organização dos processos formativos e pesquisa, que articulam-se entre si. O eixo educação e infância tem como objetivo constituir-se na dimensão integradora da formação para a docência em instituições de Educação Infantil e nos anos iniciais do Ensino Fundamental, tendo como foco a educação das crianças em instituições educativas, sejam estas creches, pré-escolas ou escolas de Ensino Fundamental. (UFSC/CED, 2008). 
Neste fim curto porque longo é o texto; porque deixo em aberto para seguirmos pensando, porque desejo ainda salientar a defesa de que:

_ O aprofundamento na compreensão de quem são as crianças e as infâncias é fundamental para pensarmos as práticas para elas voltadas a partir de um conjunto de saberes que as respeitem em suas características geracionais, cruzadas com as demais categorias: social, étnico-racial, de gênero, cultural etc e, que incorporem as suas contribuições enquanto crianças. Realizando o exercício de reconhecimento de alteridade, em que mantemos em atenção os saberes e nossos não saberes sobre as crianças, esse hiato de nossos desconhecimentos acerca delas nos dá a possibilidade de intencionalmente deixarmos espaço e tempo para a novidade da infância, a singularidade que cada sujeito criança traz ao se envolver e relacionar com nossas práticas pedagógicas nas creches e pré-escolas. Em um exercício de pensamento, no seio do próprio pensar e das práticas sociais educativas, numa nova forma de relacionar-se com o desconhecido e novidável da infância e da vida que aposta no campo da criação, invenção e da necessidade de produzirmos a diferença (PELBART, 1993).

_ A especificidade da formação docente para a educação infantil exige ser tramada numa urdidura forte e cuidada do necessário encontro entre teoria, prática e experiência (LARROSA, 2002; PAGNI, 2010; FISCHER, 2012). Considerando que a busca de um lugar para a experiência entre os saberes e práticas educativas e de suas linguagens, alternativa à atual pragmática do ensino e instrumentalismo da razão, implica em atitudes éticas e políticas dos sujeitos aos quais se destina e que as promovem, no sentido da transformação de si mesmos e de suas formas de existência. Para que possamos escapar à racionalidade totalizadora, expressão de uma resistência política ao existente e um cuidado ético de si aos sujeitos da práxis educativa (PAGNI, 2010) é necessário o saber da experiência que se dá na relação entre o conhecimento e a vida humana em um reencadeamento perpétuo da realidade (DELEUZE, 1998), e nele algo que vença a ausência de experiências sentidas e pensadas (SKLIAR, 2009).

\section{Referências}

BECCHI, Egle. Retórica da infância. Perspectiva. Revista do Centro de Ciências da Educação, Florianópolis, n.22, agosto/dez. p. 63-95, 1994.

BROERING, Adriana de S. Quando a creche e a universidade se encontram: histórias de estágio. In: OSTETTO, Luciana E. (Org). Educaçáo Infantil: saberes e fazeres da formação de professo- 
res. Campinas, SP: Papirus, 2008, p.107- 126.

CAMPOS, Maria Malta. Para que serve a pesquisa em educação? Cadernos de Pesquisa. Vol.39, n.136, pp. 269-283, 2009.

CARVALHO, José Sérgio. A teoria na prática é outra? Consideraçóes sobre as relaçóes entre teoria e prática em discursos educacionais. Revista Brasileira de Educaçáo. V. 16 n. 47 maio-ago. 2011.

CERISARA, Ana Beatriz, OLIVEIRA, Alessandra M. Rotta de, RIVERO, Andréa S. e BATISTA, Rosa. Partilhando olhares sobre as crianças pequenas: reflexóes sobre o estágio na educação infantil. Revista Zero a Seis. N.5, Janeiro/Julho, 2002.

FISCHER, Rosa M. B. "Mitologias" em torno da novidade tecnológica em educação. Educaçáo e Sociedade. Campinas, v. 33, n. 121, p. 1037-1052, out.-dez. 2012.

GATTI, Bernardete. Formação de professores no Brasil: características e problemas. Educaçáo e Sociedade, Campinas, v. 31, n. 113, p. 1355-1379, out.-dez. 2010.

KRAMER, Sônia; NUNES, Maria Fernanda R.; CORSINO, Patrícia. Infância e crianças de 6 anos: desafios das transições na educação infantil e no ensino fundamental. Educaçáo e Pesquisa [online] 2011, v. 37, n. 1, pp. 69-85. Disponível em: http://www.scielo.br/pdf/ep/v37n1/v37n1a05. pdf

LARROSA, Jorge B. Notas sobre a experiência e o saber de experiência. Revista Brasileira de Educação. n. 19, Janeiro/Abril, 2002. Disponível em: <http://www.anped.org.br/rbe/rbedigital/ RBDE19/RBDE19 04 JORGE LARROSA BONDIA.pdf>

LE BRETON, David. Paixóes ordinárias. Petrópolis, RJ: Vozes, 2009.

OSTETTO, Luciana (Org). Encontros e encantamentos na educaçáo infantil: partilhando experiências de estágios. Campinas, SP: Papirus, 2000.

PAGNI, Pedro A. Um lugar para a experiência e suas linguagens entre os saberes e práticas escolares: pensar a infância e o acontecimento na práxis educativa. In: PAGNI, Pedro A. e GELAMO (Org.), Rodrigo P. Experiência, educaçáo e contemporaneidade. Marília: Poiesis Editora, 2010, p. 15-34.

ROCHA, Eloísa A. C.; OSTETTO, Luciana E. O estágio na formação universitária de professores de educação infantil. IN: SEARA, Izabel Christine. DIAS, Maria de Fátima Sabino. OSTEETTO, Luciana Esmeralda. CASSIANI, Suzani (orgs). Práticas pedagógicas e estágios: diálogos com a cultura escolar. Florianópolis: Letras Contemporâneas, 2008, p.103-116.

Diretrizes Educacionais Pedagógicas para Educaçáo Infantil. Prefeitura Municipal de Florianópolis. Secretaria Municipal de Educação. Florianópolis: Prelo Gráfica e Editora Ltda., 2010. Disponível em: http://www.pmf.sc.gov.br/arquivos/arquivos/pdf/12 $05 \quad 2010 \quad 15.24 .41$. 03c7e67bbe979ef30c2efe7d1db1468a.pdf Acesso em: 5, maio, 2014.

30 anos da Educação Infantil na Anped: Caminhos da Pesquisa. 30a. Reuniáo Anual da Anped. Trabalho encomendado. Gt 07, Caxambu-MG, 2007.

. Infância e Educação: novos estudos, velhos dilemas da pesquisa educacional e a relaçáo com a Educação Básica. ANPED Sul, 2012.

SANTOS, (1990). O Estado e o direito na transição pós-moderna: para um novo senso comum sobre o poder e o direito. Revista Crítica de Ciências Sociais, Portugal, no 30, junho.

UFSC/CED. Projeto Político Pedagógico do Curso de Pedagogia, 2008. 